\title{
Mechanical and Processing Properties of Rice Grains
}

\author{
Weronika Kruszelnicka ${ }^{1} * \mathbb{0}$, Andrzej Marczuk ${ }^{2}$, Robert Kasner ${ }^{1}$, Patrycja Bałdowska-Witos ${ }^{1}$, \\ Katarzyna Piotrowska ${ }^{3}{ }^{\circledR}$, Józef Flizikowski ${ }^{1}$ and Andrzej Tomporowski ${ }^{1}$ \\ 1 Department of Manufacturing Techniques, Faculty of Mechanical Engineering, University of Science and \\ Technology in Bydgoszcz, 85-796 Bydgoszcz, Poland; robert.kasner@gmail.com (R.K.); \\ patrycja.baldowska-witos@utp.edu.pl (P.B.-W.); fliz@utp.edu.pl (J.F.); a.tomporowski@utp.edu.pl (A.T.) \\ 2 Faculty of Production Engineering, University of Life Sciences in Lublin, 20-612 Lublin, Poland; \\ andrzej.marczuk@up.lublin.pl \\ 3 Faculty of Mechanical Engineering, Lublin University of Technology; 20-618 Lublin, Poland; \\ k.piotrowska@pollub.pl \\ * Correspondence: weronika.kruszelnicka@utp.edu.pl
}

Received: 17 November 2019; Accepted: 9 January 2020; Published: 11 January 2020

\begin{abstract}
Strength properties of grains have a significant impact on the energy demand of grinding mills. This paper presents the results of tests of strength and energy needed the for destruction of rice grains. The research aim was to experimentally determine mechanical and processing properties of the rice grains. The research problem was formulated in the form of questions: (1) what force and energy are needed to induce a rupture of rice grain of the Oryza sativa L. of long-grain variety? (2) what is the relationship between grain size and strength parameters and the energy of grinding rice grain of the species Oryza sativa L. long-grain variety? In order to find the answer to the problems posed, a static compression test of rice grains was done. The results indicate that the average forces needed to crush rice grain are $174.99 \mathrm{~kg} \mathrm{~m} \cdot \mathrm{s}^{-2}$, and the average energy is $28.03 \mathrm{~mJ}$. There was no statistically significant relationship between the grain volume calculated based on the volumetric mass density $V_{\rho}$ and the crushing energy, nor between the volume $V_{\rho}$ and other strength properties of rice grains. In the case of Vs, a low negative correlation between strength $\sigma_{\text {min }}$ and a low positive correlation between the power inducing the first crack were found for the grain size related volume. A low negative correlation between the grain thickness $a_{3}$, stresses $\sigma_{\text {min }}$ and work $W_{\text {Fmax }}$ was found as well as a low positive correlation between thickness $a_{3}$ and the force inducing the first crack $\boldsymbol{F}_{\text {min }}$.
\end{abstract}

Keywords: rice; grinding; compressive strength; rupture energy

\section{Introduction}

The strength properties of grains have a significant impact on the energy demand of grinders [1-4]. During grinding of grains in a five-disc mill, a complex state of stress occurs in the material, with shear and compressive stresses prevailing [5,6]. Identification of the forces causing grain cracking (rupture) can be considered as the first step to determine the energy demand in the grain grinding process $[7,8]$. Two cases can be distinguished: static squeezing of grains and shearing of grains [9]. In the case of static compression, in order to determine the forces and stress and consequently, the work (energy) needed to crush one grain and then more than a dozen grains, a static compression test can be carried out. The ranges of probable forces destroying the grain may be determined in an experimental manner, and subsequently, the energy ranges of destroying its structure [10].

The subject of research on the physical-mechanical properties of rice grains has already been addressed by researchers, because the specificity of rice grain processing and the energy demand of processing lines, e.g., grinding, drying, pelleting, etc., depends largely on these properties [11-17]. In their research, Zeng, et al. [18] focused on modeling cracking of rice grains depending on the grain 
moisture and load speed, using the Discrete Element Method (DEM). The impact of humidity on the strength properties of white rice was also addressed in the work of Sadeghi et al. [19], and brown rice in the work by Cao et al. [20] and Chattopadhyay et al. [21]. Buggenhout et al. [22] studied the influence of physicochemical properties, in particular, the impact of grain husks and moisture on cracking phenomena during rice processing. Esehaghbeygi et al. [23] in turn, analyzed the effect of drying temperature and kinetic energy during the drying process on grain susceptibility to breaking. Similar research was conducted by Sarker et al. [24], Tajaddodi et al. [25], Nasirahmadi et al. [26] and Bonazzi and Courtois [27]. The influence of grain orientation on its mechanical properties under load was analyzed, among others, by Li et al., Shu et al., and Zareiforoush et al. [28-30]. They showed that rice grains are more flexible in horizontal orientation based on the results of static compression and three-point bending tests. Zareiforoush et al. [31], based on the conducted research, found that increasing the speed of load during the compression test results in lowering crushing forces and energy.

From the point of view of energy demand, processing of grainy biomaterials, particularly grinding, the strength of grains plays the key role. [32]. Considering the process of grinding, e.g., by means of grinding machines or roller mills, these are the compressive loads which prevail in the grinded material, whereas permanent deformation (fragmentation) occurs after exceeding the load value corresponding to the compressive strength limit. Strength is closely related to the power necessary to cause the strain and the grinded material cross-section field (hence being dependent on its geometric features). Thus, material fragmentation occurs upon application of appropriate forces, which, in the system of grinding machines, roller mills, is performed by rotary motion of rollers. In such a case, the force is a direct effect of torques, which, in turn, are related to the power of the devices affecting the energy demand of the grain processing. In general, the higher force to be applied the higher power, that is, the machine energy, is needed. The aspects concerning calculation of energy demand for grain grinding systems are described in detail in [33].

The strength of grains depends on the type of material, especially on its internal structure (porosity), moisture, components of the grain, and biological properties [34]. In the case of biomass grains, a significant diversification in terms of dimensions, physical and strength properties, can be observed even within one grain species which, apart from biological characteristics, is conditioned by the weather conditions and the cultivation method [35-37] Earlier research has shown that the energy needed to grind hard materials with higher strength is larger [38-40]. It was also observed that along with a moisture increase, the energy consumption increases as well [18-20,36]. The internal structure of the grain endosperm and tegument has an impact on the strength properties and the energy needed for grinding. The endosperms which are characterized by higher glassiness are usually harder; thus, for permanent deformation, it is necessary to use higher forces which, in turn, results in an increased energy demand as compared to materials whose endosperm is less glassy [36,41,42]. The glassiness of the endosperm also has an influence on the material fragmentation efficiency and the size of particles after division - the higher glassiness, the easier to separate the endosperm from bran and the grain disintegrates into smaller parts. [38,42]. Tests of physical properties and grinding energy, carried out for wheat grains have also revealed that the grinding energy is proportional to the grinded material mass [35]. Dziki and Laskowski [37] indicate, using the example of wheat, that the values of work and force to be applied for crushing the grain increase along with the grain thickness growth.

This study contains an analysis of strength properties of rice grains, mainly forces causing the first violation of the grain structure (first crack) and grain stiffness.

The aim of the research is to experimentally determine the mechanical and processing properties (strength and energy properties) of granular biomass (rice) accepted for research in the project "Intelligent monitoring of the grinding characteristics of grainy biomass". Determining the forces needed to break grains is of key importance when developing energy and environmental efficiency indicators for the grinding process and modeling grinding and crushing processes using the discrete element method DEM. 
The research problem was formulated in the form of questions: (1) what strength and energy is needed to induce a rupture of rice grain of the species Oryza sativa L. long-grain variety? (2) what is the relationship between grain size and strength parameters and the energy of grinding rice grain of the species Oryza sativa L. long-grain variety?

\section{Materials and Methods}

\subsection{Rice Grains Preparation}

To determine the force needed to break the grain, a static compression test was carried out for 100 grains of rice of the species Oryza sativa L., a long-grained variety with a stabilized humidity equal to $13 \% \pm 0.1 \%$. Oryza sativa $\mathrm{L}$., a long-grained variety of rice was accepted to be the research object due to its popularity, among others, in food industry [32]. Knowing the processing properties of this species, in particular, crushing energy, can significantly affect power demand of the processing devices, e.g., grinders. Samples of 100 individual rice grains were prepared and described by numbers (Figure 1). Then, three dimensions were measured with the vernier caliper: length, width and height of the grain.

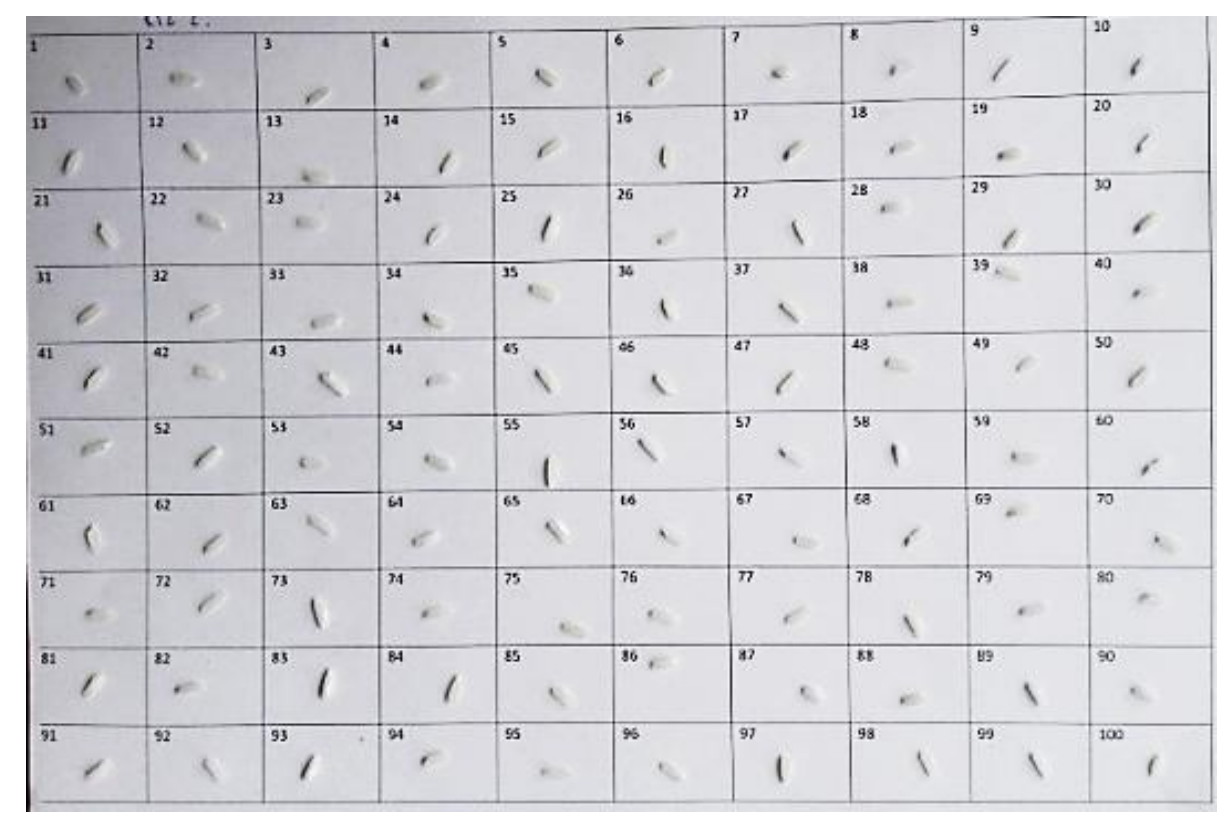

Figure 1. Rice grains prepared for compression test.

\subsection{Test Stand}

A static compression test was carried out on an Instron 5966 testing machine (Figure 2). The samples were placed in the machine in a horizontal orientation, in such a way that the dimensions $a_{1}$ and $a_{2}$ were the large axis and small axis of cross-sectional areas of the grain subjected to the load (Figure 3 ). The load speed was $2 \mathrm{~mm} \cdot \mathrm{min}^{-1}$. 


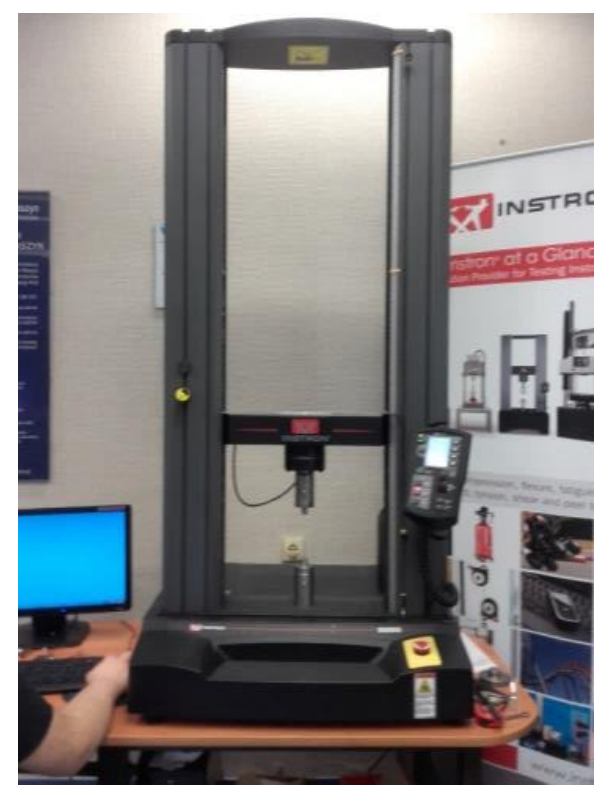

Figure 2. The Instron 5966 testing machine.

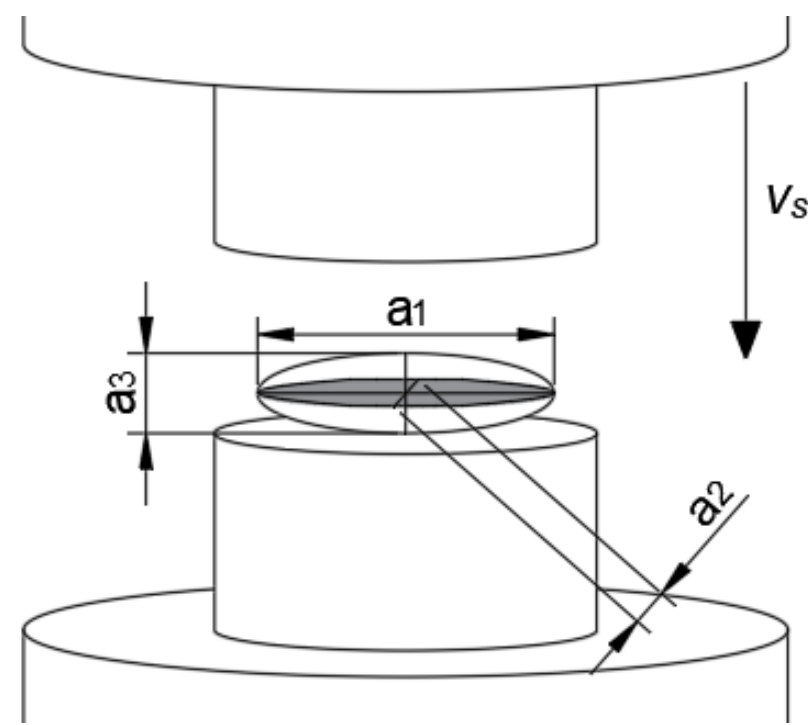

Figure 3. Position of the rice grain during the static compression test.

\subsection{Research Methods}

The analysis of the grain strength properties during a static compression test of a single grain was performed according to the plan shown in Figure 4. Three dimensions were measured with the vernier caliper: length, width and height of the grain. 


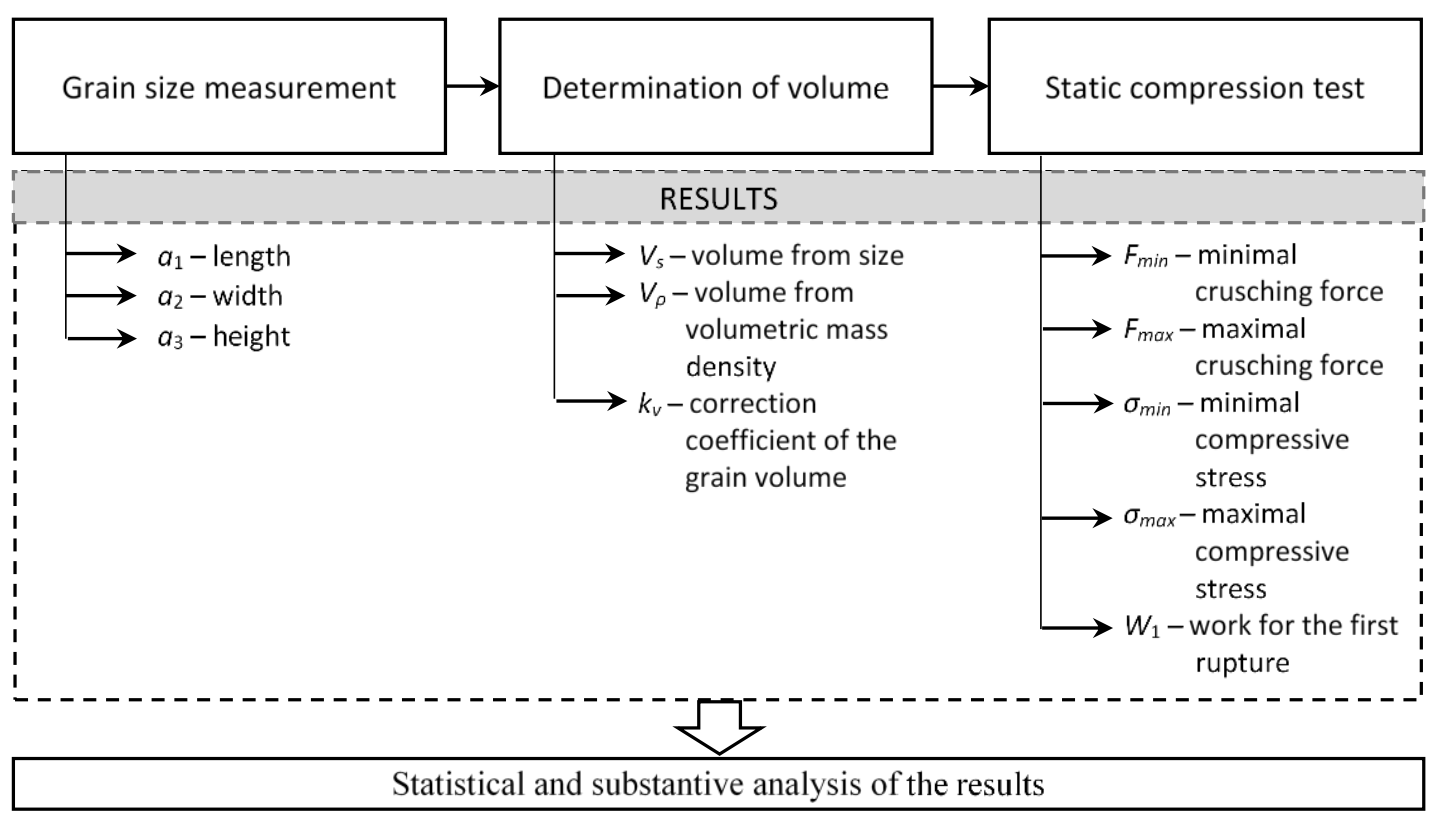

Figure 4. Plan and research program.

The volume of the studied seeds was determined in two ways: on the basis of the three measured dimensions $a_{1}, a_{2}$ and $a_{3}\left(V_{s}\right)$ and on the basis of the relationship of the grain mass and density $\left(V_{\rho}\right)$.

The first method of determining the volume takes into consideration three basic grain sizes, i.e., the height and width length, and allows a simplified grain volume estimation with a certain error by aligning the grain shape to the cuboid with dimensions $a_{1}, a_{2}, a_{3}$ (Figure 5).

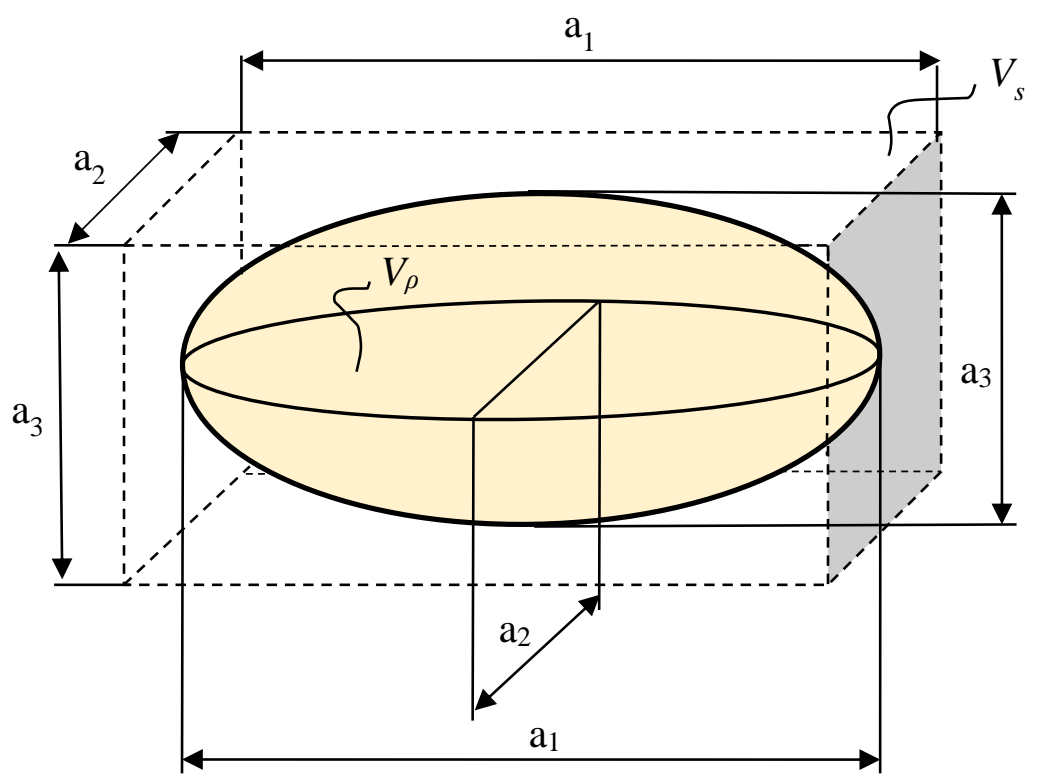

Figure 5. Graphical representation of grain volume determination based on the knowledge of three dimensions, $a_{1}$-length of the grain, $\mathrm{mm}, a_{2}$-width of the grain, $\mathrm{mm}, a_{3}$-height of the grain, $\mathrm{mm}$, vs. - grain volume calculated based on three dimensions $a_{1}, a_{2}, a_{3}$ (volume of a cuboid with dimensions $\left.a_{1}, a_{2}, a_{3}\right), \mathrm{mm}^{3}, V_{\rho}$-grain volume calculated based on the volumetric mass density, $\mathrm{mm}^{3}$.

For this interpretation, the formula for the estimated volume of grain will be:

$$
V_{s}=a_{1} \cdot a_{2} \cdot a_{3},
$$


and equal to the volume of a cuboid circumscribed on the grain.

The second method of determining the volume is based on the knowledge of density $\rho$ of the grain and its mass $m$. The grain density is determined from the dependence [43]:

$$
\rho=m / V_{\rho}
$$

Hence, the volume determined on the basis of density $V_{\rho}$, will be [43]:

$$
V_{\rho}=m / \rho,
$$

The relationship between computational volume $\left(V_{s}\right)$ and determined based on the grain density $\left(V_{\rho}\right)$ can be determined by calculating the correction factor for the grain volume $k_{v}$ taking into consideration the grain spherical and uneven shape. It can be determined experimentally and expressed by the dependence:

$$
k_{v}=V_{\rho} / V_{s}
$$

hence:

$$
V_{\rho}=k_{v} \cdot V_{s}
$$

The static compression test is mainly used for brittle materials, i.e., not showing significant plastic deformation. Rice can be considered as a fragile material with some (small) plastic deformability due to the internal structure that differentiates it from the cross-linked metal structure. A feature that characterizes fragile materials is compressive strength $\left(R_{c}\right)$ [24]:

$$
R_{c}=F_{c} / A_{0}
$$

where

$F_{c}$ - the largest value of the compressive load at which the sample is crushed,

$A_{0}$-the initial cross-section of the sample.

If the compression diagram $l=f(F)$ has a part where shortening $(\Delta l)$ is directly proportional to compressive force $(F)$, then, on this basis, we determine Young's modulus $(E)$ for this material. If this relationship is not directly proportional, then based on the first few results (where it is possible to assume that the material behaves linearly and elastically), we determine the mean value of Young's modulus $(E)$. The value of the Young's modulus is determined by Hooke's law [24]:

$$
E=F \cdot l /\left(\Delta l \cdot A_{0}\right),
$$

where:

F-compressive force, $\mathrm{kg} \cdot \mathrm{m} \cdot \mathrm{s}^{-2}$,

$\Delta l$-sample shortening corresponding to force $(F), \mathrm{m}$,

$l$-the initial length of the sample, $\mathrm{m}$,

$A_{0}$-area of the initial sample cross-section, $\mathrm{m}^{2}$.

During the compression, some force $F$ affects the grain and causes it to break (displacement $s$ ), so the elementary work done over the grain by force $F$ causing the crack can be determined $[24,44]$ :

$$
d W=F \cdot d s .
$$

During compression, we deal with a variable force $F$ and displacement $s \rightarrow 0$, then, this characterized work can be determined by integrating both sides of the equation [24]:

$$
W=\int_{s_{1}}^{s_{2}} F d s
$$


Then, the work during compression of one grain is the area under graph $F=f(s)$ (Figure 6).

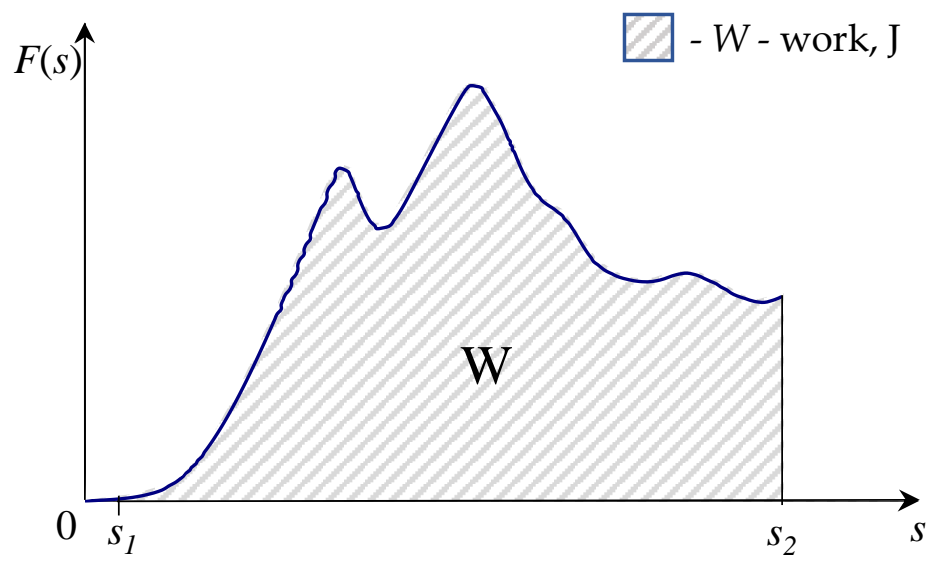

Figure 6. Graphic presentation of work during compression of grains, $F(\mathrm{~s})$ — compressive force, $\mathrm{kg} \cdot \mathrm{m} \cdot \mathrm{s}^{-2}$, $\mathrm{s}$-displacement, $\mathrm{m}, \mathrm{W}$-work, J, $\mathrm{s}_{1}$-starting point of displacement, $\mathrm{m}, \mathrm{s}_{2}$-final displacement, $\mathrm{m}$.

\subsection{Analytical Methods}

The statistical analysis tools available in MS Excel and Statistica were used in processing the results. Basic descriptive statistics of the examined physical and mechanical properties and rupture energy of rice grains were determined. The relationship between the grain volume and physical-mechanical properties and rupture energy was examined using Spearman's correlation analysis. A significance level $p<0.05$ was adopted.

\section{Results and Discussion}

\subsection{Results of Research on the Physical Properties of Rice Grains and Their Discussion}

Firstly, the physical properties of rice grains were determined, such as grain length $a_{1}$, grain width $a_{2}$, grain height $a_{3}$, and grain volume determined based on the knowledge of grain mass and density $V_{\rho}$, volume determined on the basis of dimensions $V_{s}$, correction factor for volume $k_{v}$. The results of the tests after a basic statistical analysis are presented in Figures 7 and 8 in the form of a box plot.

Based on the analysis, it was found that the average grain length of rice was $6.38 \mathrm{~mm}$, the average width was $1.91 \mathrm{~mm}$, the average height was $1.51 \mathrm{~mm}$. The average grain volume determined on the basis of the grain weight and density was equal to $14.82 \mathrm{~mm}^{3}$, while the volume determined on the basis of grain size $18.44 \mathrm{~mm}^{3}$. The correction factor for given volumes $V_{\rho}$ and vs. assumed an average value of 0.82 . The obtained results allowed to formulate the dependence of the real volume of the grain determined on the basis of density as a function of the volume determined on the basis of dimensions:

$$
V_{\rho}=k_{v} \cdot V_{s}=0.82 \cdot V_{s}
$$

The results obtained for rice dimensions $a_{1}, a_{2}$, and $a_{3}$, are similar, although slightly smaller than those reported in the literature by other researchers, e.g., Sadeghi et al., Zareiforoush et al., and Zeng et al. $[18,19,30]$. Differences in dimensions may be caused primarily by the difference in the varieties and types of rice grains studied, the country of origin (the study of rice originated from Burma), grain humidity and growing conditions of grains (e.g., extensive, intensive cultivation, weather conditions that affect the grain size). The presented grain size results are an indispensable element of building models in computer simulations based on the DEM discrete element method [18], e.g., in the RockyDEM environment. 

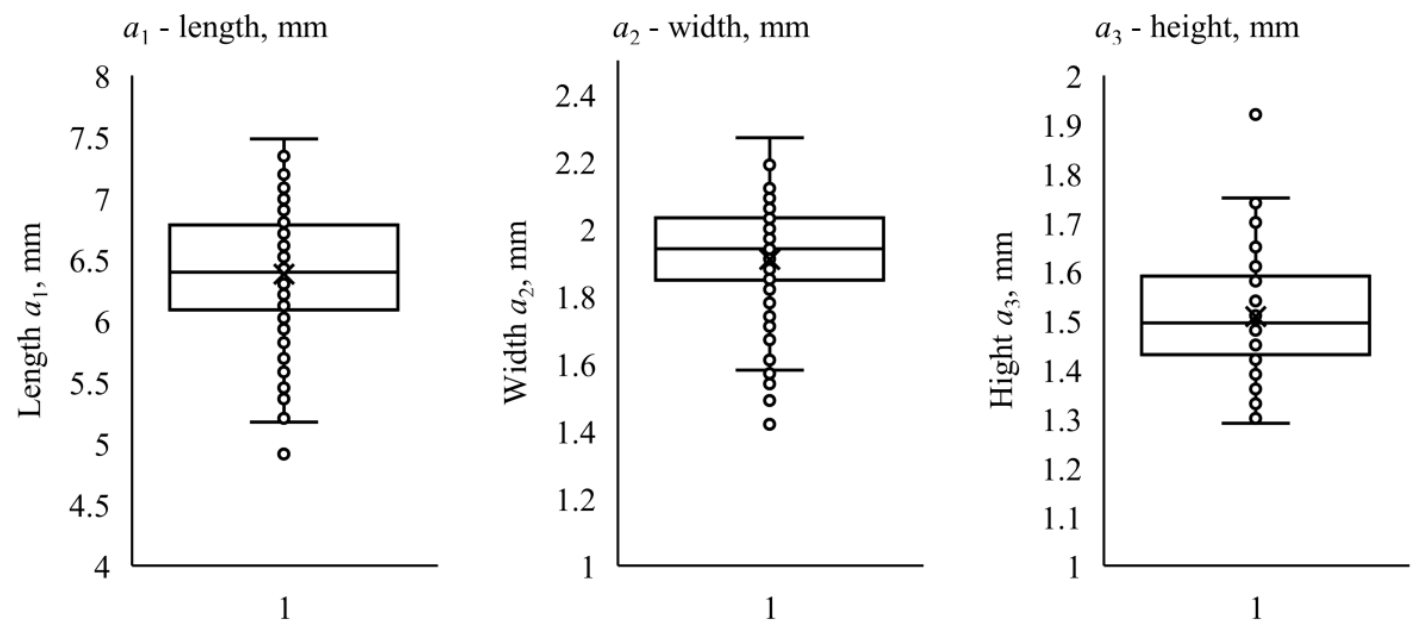

Figure 7. Results of the rice grains size determination.
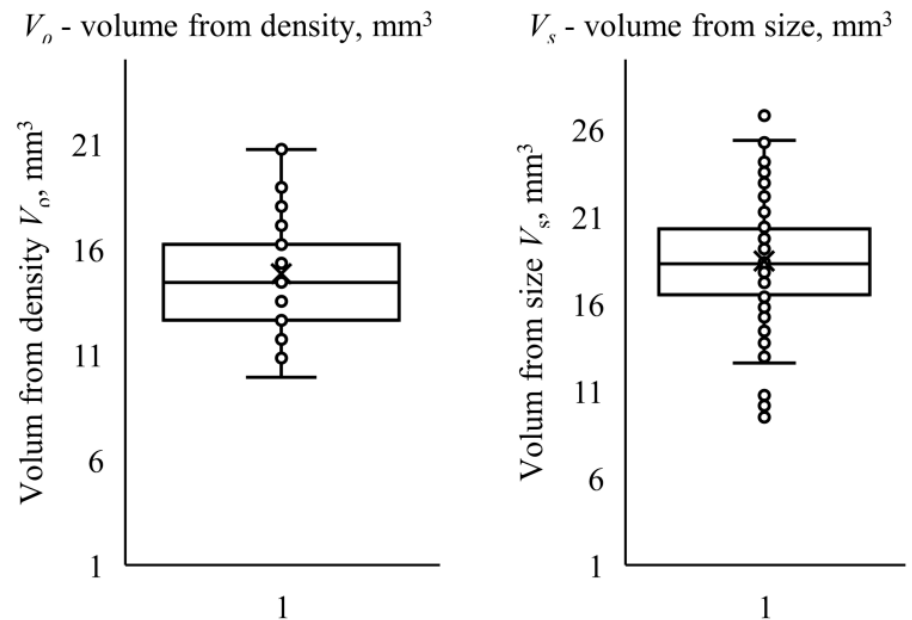

$$
\begin{gathered}
k_{v} \text { - correction coefficient of } \\
\text { volume }
\end{gathered}
$$

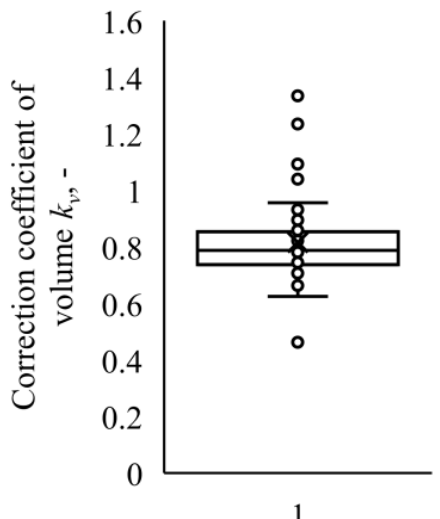

Figure 8. Results of rice grains volume determination.

\subsection{The Results of Testing the Strength Properties of Rice Grains and Their Discussion}

Figure 9 presents examples of graphs showing the characteristic of rice grain cracks during a compression test. Based on the presented curves, it can be stated that for each grain, the crack proceeded differently. This is caused by differences in internal structure between each grain, which is characteristic for biomaterials. However, noticeable are the characteristic points in the force-displacement graph marked as $F_{\min }$ and $F_{\max }$. The point marked as $F_{\min }$ symbolizes the first crack of the grain, while the $F_{\max }$ point corresponds to the forces causing the breakdown of the grain into smaller fragments (Figure 10). Similar conclusions are presented in the work of Sadeghi et al. [19].

For rice grains, the forces inducing fracture $F_{\min }$ of the grain structure were within the range (35.86-198.71) $\mathrm{kg} \mathrm{m} \mathrm{s}^{-2}$. The maximum forces $F_{\max }$ during the crack growth for rice were within the range (70.05-535.74) $\mathrm{kg} \mathrm{m} \mathrm{s}^{-2}$. Stresses $\sigma_{\min }$ for rice were in the range (2.21-17.38) MPa. Stresses $\sigma_{\max }$ for rice were in the range (5.00-29.61) MPa. Work $W_{F m i n}$ for rice was in the range (1.88-56.55) $\mathrm{mJ}$ and $\mathrm{W}_{\text {Famx }}$ in the range (2.53-98.93) $\mathrm{mJ}$ (Figure 11). 


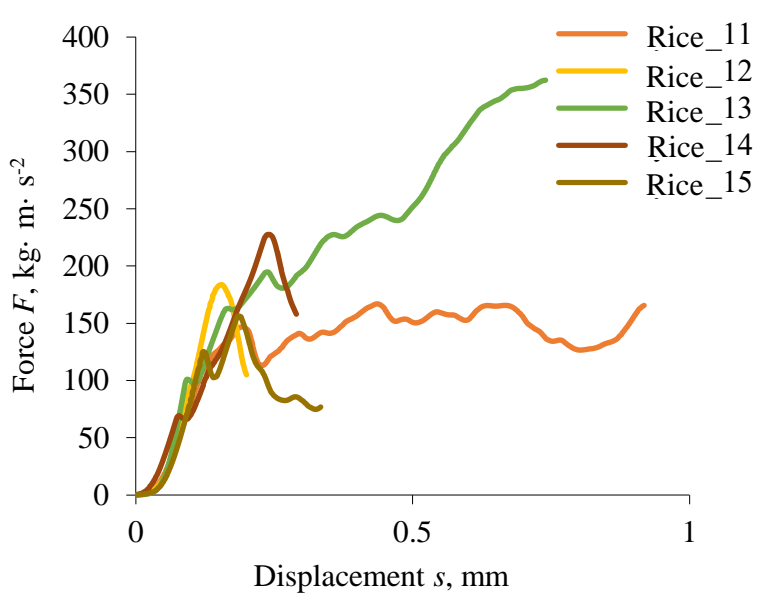

Figure 9. Exemplary curves for five rice grains from 100 tested illustrating the course of the rice grain compression process in the force-displacement coordinate.

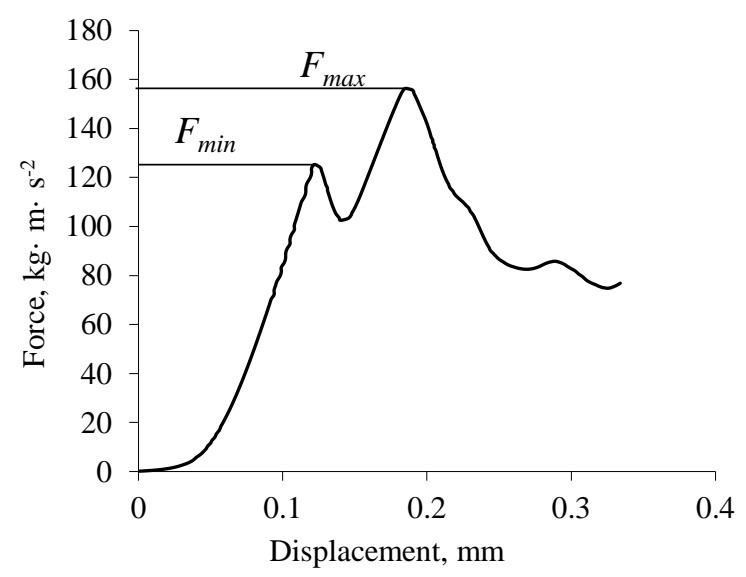

Figure 10. The cracking process for rice grains in function $F(s)$.

$F_{\text {min }}$ - minimal crushing force, $\mathrm{kg} \cdot \mathrm{m} \cdot \mathrm{s}^{-2}$

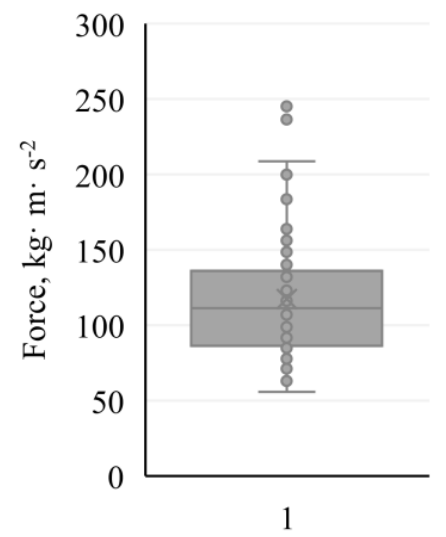

$\sigma_{k m i n}-$ minimal compressive stress, MPa

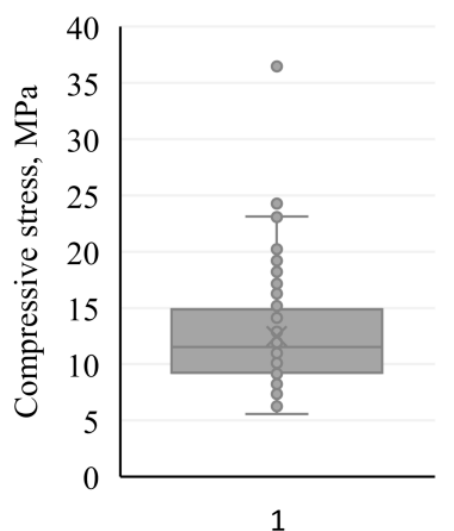

1
$W_{F \min }-$ work for the first rupture, $\mathrm{mJ}$

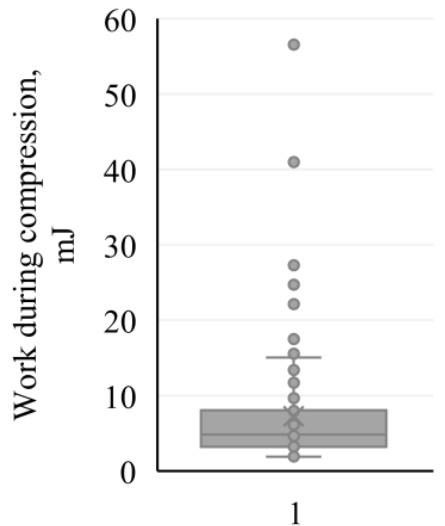

Figure 11. Cont. 
$F_{\max }-$ maximal crushing force, $\mathrm{kg} \cdot \mathrm{m} \cdot \mathrm{s}^{-2}$

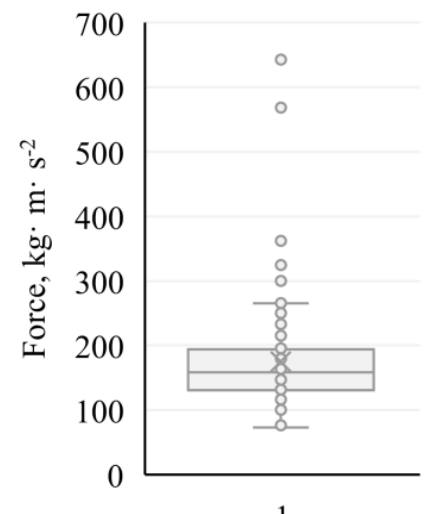

$\sigma_{\text {kmax }}-$ maximal compressive stress, $\mathrm{MPa}$

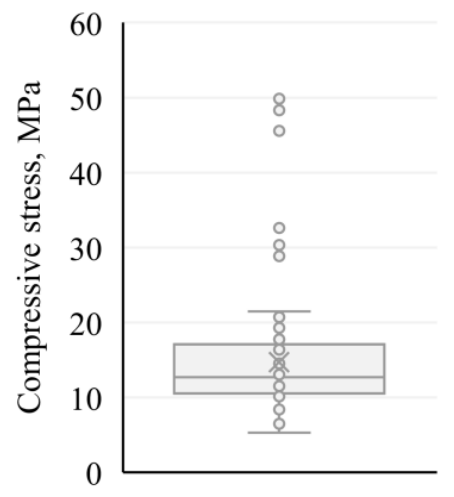

1

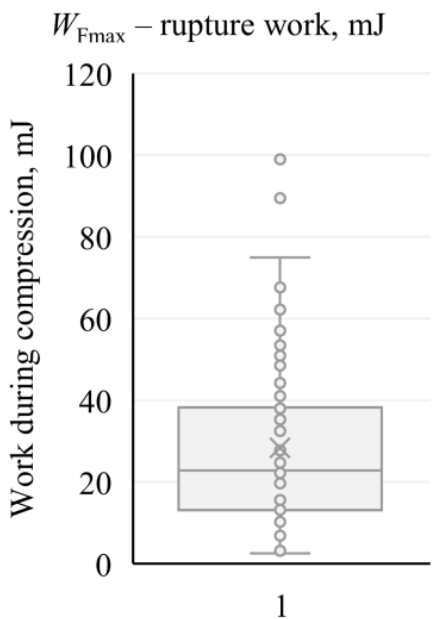

Figure 11. Results of statistical analysis of forces, stresses and energy during compression of rice grains.

Table 1 presents average values and basic results of a statistical analysis of the surveyed quantities. The obtained mean values of forces $F_{\max }$ are in accordance with the results presented by $\mathrm{Lu}$ and Siebenmorgen [45] obtained in the compression test at the load speed vs. $2 \mathrm{~mm} \cdot \mathrm{min}^{-1}$ $\left(174.4-188.8 \mathrm{~kg} \cdot \mathrm{m} \cdot \mathrm{s}^{-2}\right)$, and higher than in the tests carried out by Sadeghi et al. [19] $\left(169.06 \mathrm{~kg} \cdot \mathrm{m} \mathrm{s}^{-2}\right.$ for the Sorkheh type and $125.10 \mathrm{~kg} \cdot \mathrm{m} \cdot \mathrm{s}^{-2}$ for the Sazandegi type with $v_{s}=1,25 \mathrm{~mm} \cdot \mathrm{min}^{-1}$ ), by Zareiforoush et al. [31] (125.69 $\mathrm{kg} \cdot \mathrm{m} \cdot \mathrm{s}^{-2}$ for the Alikazemi type and $109.96 \mathrm{~kg} \cdot \mathrm{m} \cdot \mathrm{s}^{-2}$ for the Hashemi type with $v_{s}=5 \mathrm{~mm} \cdot \mathrm{min}^{-1}$ and $117.38 \mathrm{~kg} \mathrm{~m} \mathrm{~s}{ }^{-2}$ for the Alikazemi type and $88.33 \mathrm{~kg} \mathrm{~m} \cdot \mathrm{s}^{-2}$ for the Hashemi type with $v_{s}=10 \mathrm{~mm} \cdot \mathrm{min}^{-1}$ ). Differences in the obtained values may result from different grain moistures, loading speeds of the samples and the type of rice used in the tests.

Table 1. Results of statistical analysis of examined mechanical properties of rice grains.

\begin{tabular}{cccc}
\hline Parameter & Average & Standard Deviation & Median \\
\hline Minimal crushing force $F_{\min }, \mathrm{kg} \mathrm{m} \cdot \mathrm{s}^{-2}$ & 117.29 & 40.71 & 111.23 \\
Maximal crushing force $F_{\max }, \mathrm{kg} \cdot \mathrm{m} \cdot \mathrm{s}^{-2}$ & 174.99 & 80.38 & 158.12 \\
Minimal compressive stress $\sigma_{\mathrm{kmin}}, \mathrm{MPa}$ & 12.47 & 4.83 & 11.53 \\
Maximal compressive stress $\sigma_{\mathrm{kmax}}, \mathrm{MPa}$ & 14.71 & 7.45 & 12.72 \\
Stiffness $C_{k}, \mathrm{~N} \cdot \mathrm{mm}^{-1}$ & 1275.07 & 247.72 & 1322.11 \\
Work for the first rupture $W_{\text {Fmin }}, \mathrm{mJ}$ & 7.26 & 7.86 & 4.81 \\
Rupture work $W_{\text {Fmax }}, \mathrm{mJ}$ & 28.03 & 20.36 & 22.46 \\
\hline
\end{tabular}

The average value of rupture work $W_{\text {Fmax }}(28.03 \mathrm{~mJ})$ is similar to the values presented, among others, in the work of Nasirahmadi et al. [26] (26.9 mJ for Fajr and $28.5 \mathrm{~mJ}$ for Tarom) and Sadeghi et al. [19] (24.45 mJ for Sazandegi) as well as in the work of Zareiforoush et al. [30,31], where the rupture energy assumed values of about $30 \mathrm{~mJ}$.

Figures 12-18 summarize the results of mechanical properties of rice grains depending on its volume. The graphs show that mechanical properties of rice grains do not depend on its volume. 


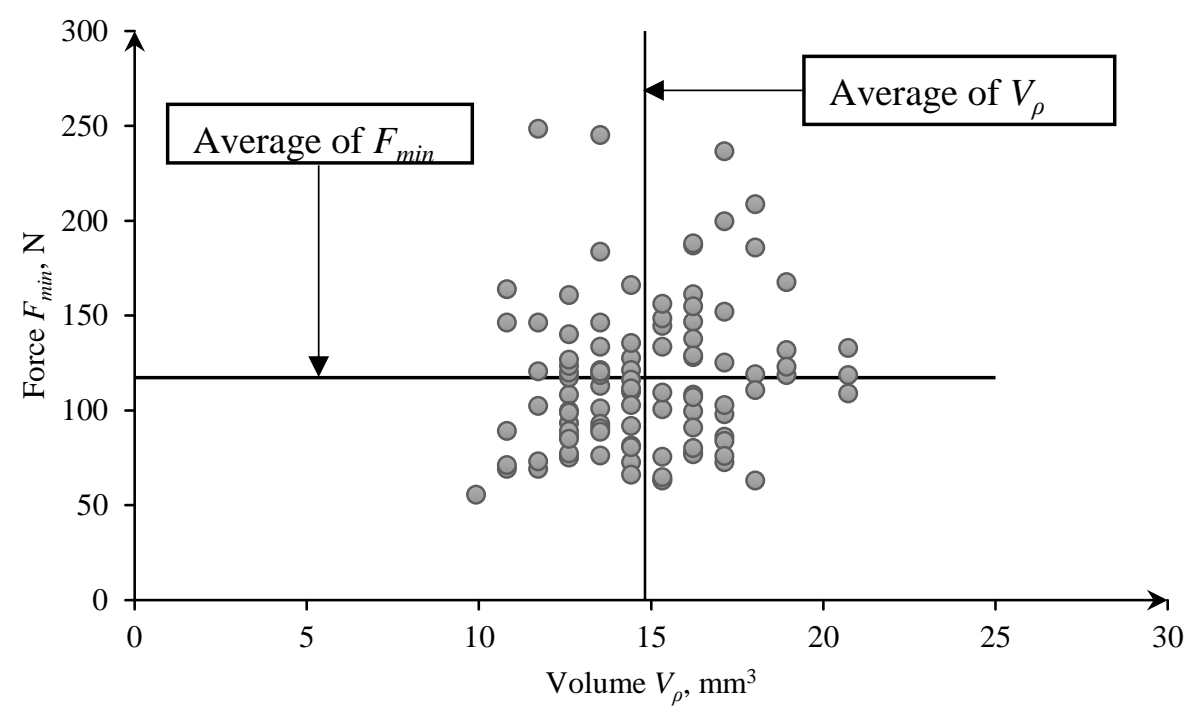

Figure 12. The scatter diagram of forces $F_{\min }$ for individual rice grains in relation to volume.

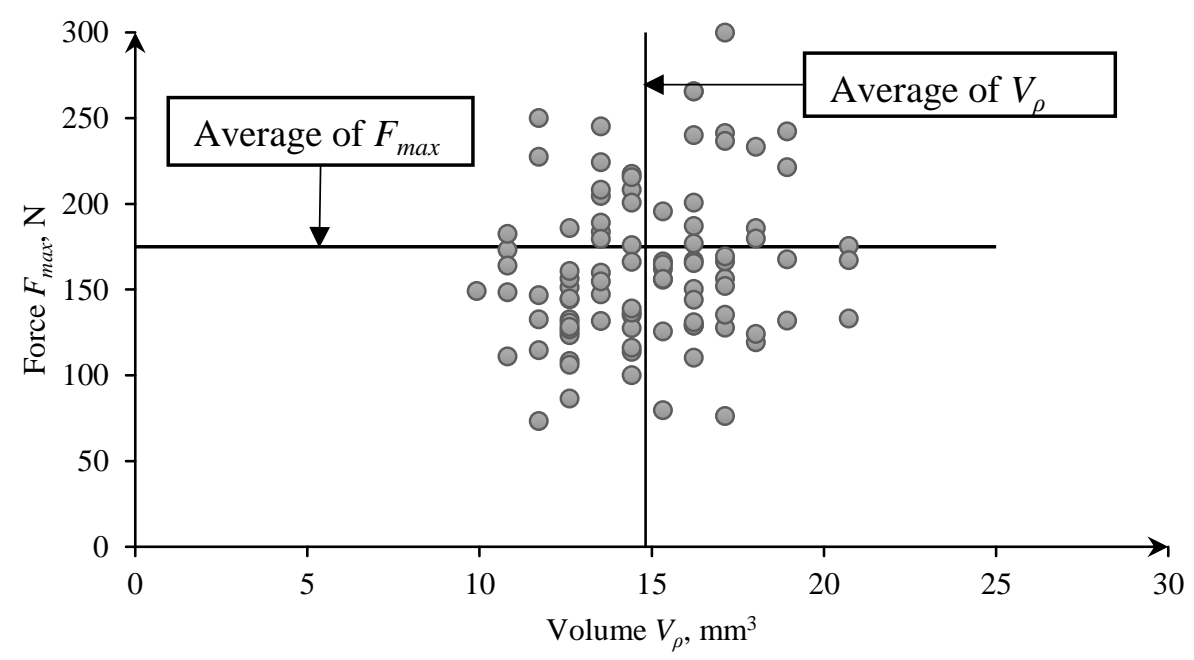

Figure 13. The scatter diagram of forces $F_{\max }$ for individual rice grains in relation to volume.

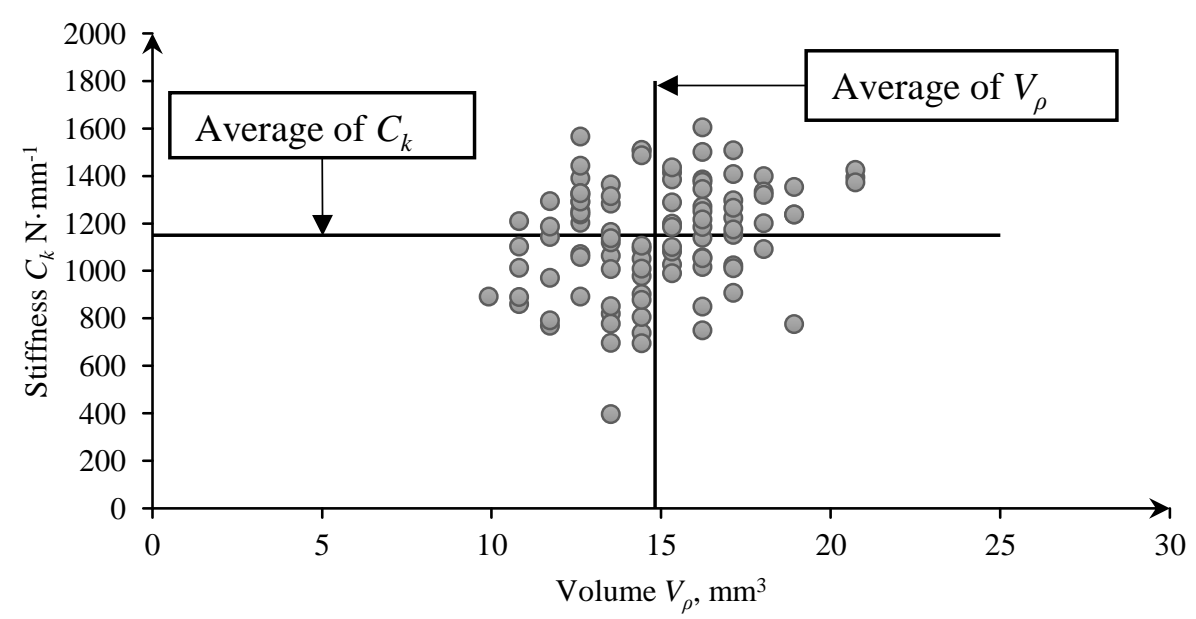

Figure 14. The scatter diagram of stiffnes for individual rice grains in relation to volume. 


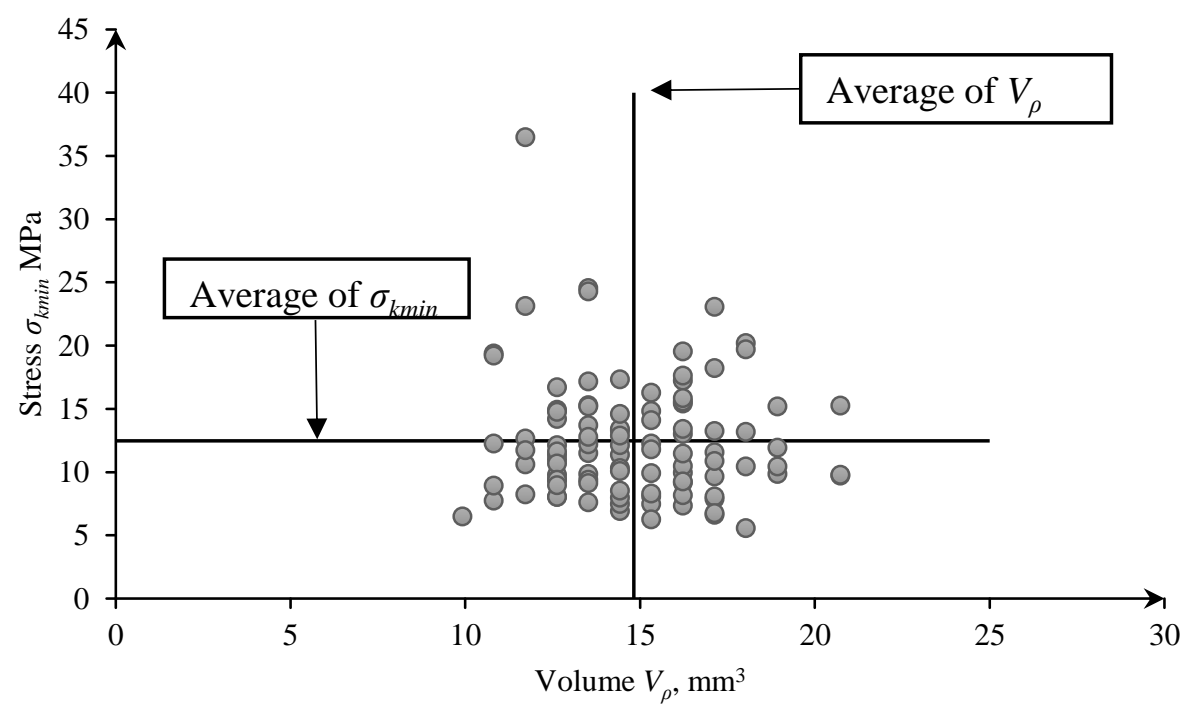

Figure 15. The scatter diagram of stress $\sigma_{k m i n}$ for individual rice grains in relation to volume.

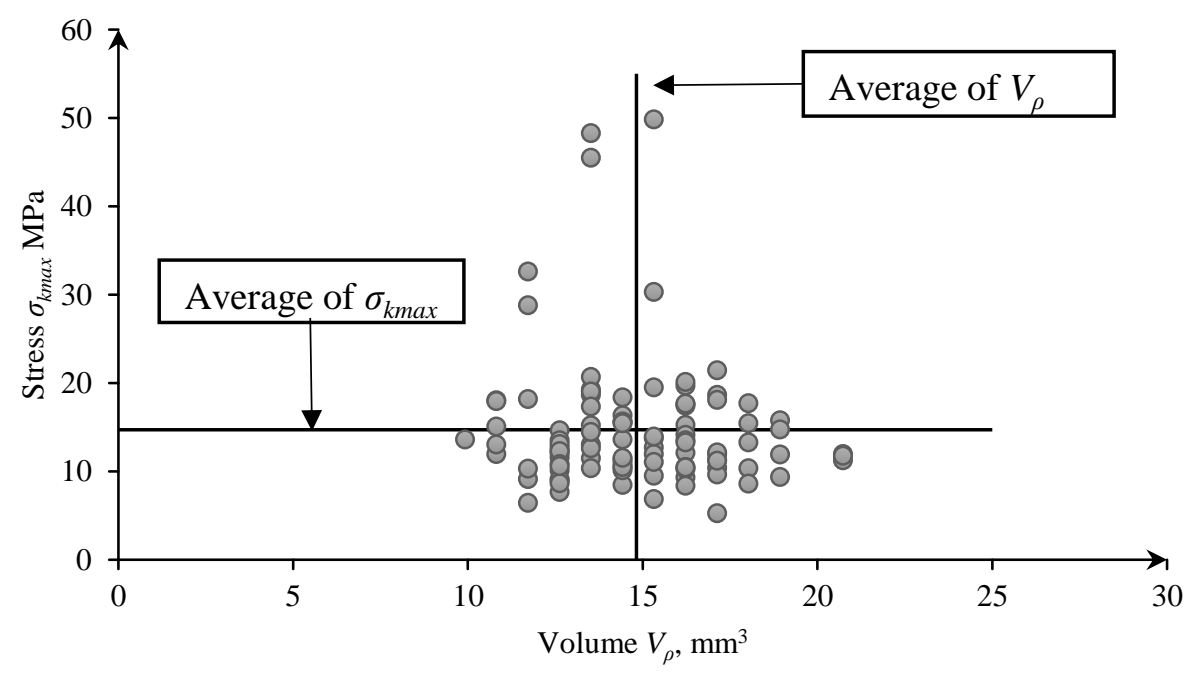

Figure 16. The scatter diagram of stress $\sigma_{k m a x}$ for individual rice grains in relation to volume.

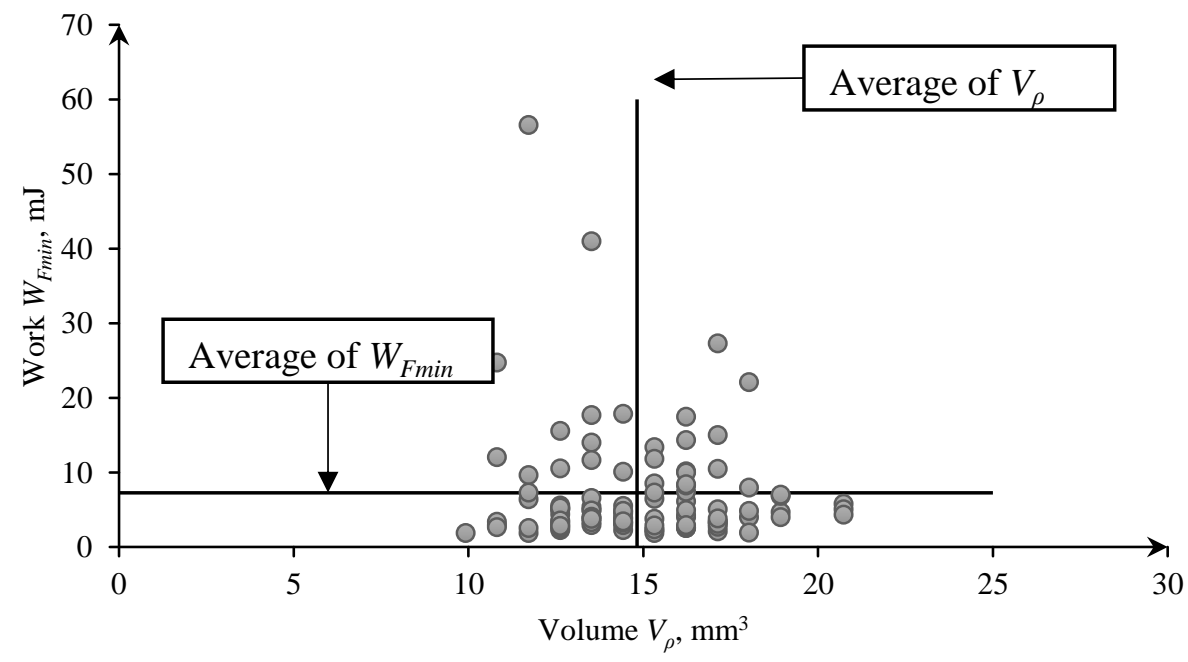

Figure 17. The scatter diagram of stress $W_{F m a x}$ for individual rice grains in relation to volume. 


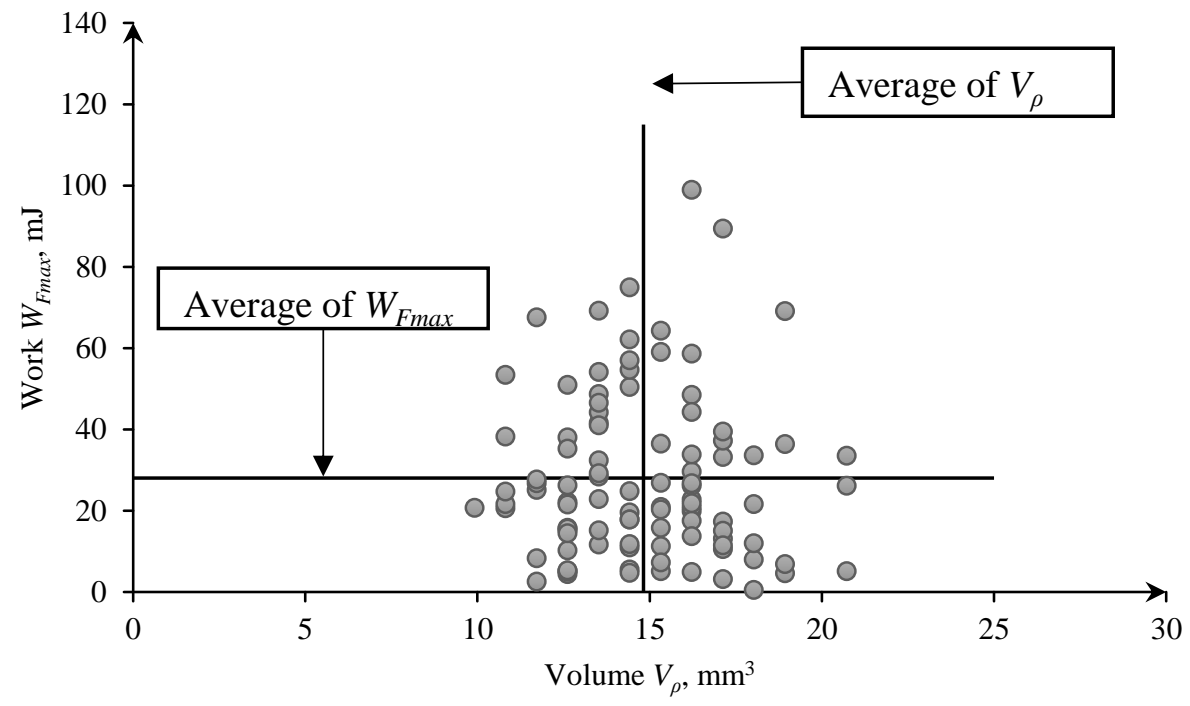

Figure 18. The scatter diagram of stress $W_{F \max }$ for individual rice grains in relation to volume.

The analysis of the Spearman correlation shows that there are no statistically significant relationships between the volume of the grain $V_{\rho}$ and the tested strength properties, so there are no interdependencies between the variables (Tab 2). In the case of the grain dimension related volume vs. a low negative correlation between strength $\sigma_{\min }$ and low positive correlation between the force inducing the first crack were found (Table 2). An analysis of the correlation between the grain size related variables, that is, length $a_{1}$, width $a_{2}$, height $a_{3}$, mass $m$ and volumes $V_{\rho}$ and vs. showed that the volume of grains $V_{\rho}$ is moderately positively correlated with length $a_{1}$ and height $a_{3}$ (Table S1). The surface of compression cross-section $A_{0}$ was in turn significantly correlated with the grain length $a_{1}$ and width $a_{2}$ (Table S1). However, no relevant correlations between the grain dimensions, volume and mass and its strength properties and energy needed to crush the grains, were found. Only low correlations occurred, including negative ones between the grain width $a_{2}$ and stresses $\sigma_{\min }$ and $\sigma_{\max }$ (Table S1). Contrarily to wheat, a dependence of grinding energy proportionality and its mass was not confirmed [35]. It was not possible to confirm distinct dependencies between the grain thickness $\left(a_{3}\right)$ and the force value, either (for $F_{\min }$ positive correlation $R=0.271$, statistically significant $p<0.05$, for $F_{\max }$ statistically insignificant correlation (Table S1)) and work ( $W_{F \min }$ and $W_{\text {Fmax }}$ low correlations), which could be observed for wheat [37]. The volume is related to the grain dimensions, including compression cross-section $A_{0}$, whereas the cross section is related to compressive strength (according to dependence (6)). However, it was not possible to show significant dependencies between the grain cross section $A_{0}$ and values of compressive strength (low negative correlations between $A_{0}$ and $\sigma_{\text {min }}$, $\sigma_{\max }$ (Table S1)). The obtained results, including the results of dimension and volume scatter, confirm the significant variability and diversity of biological materials within one species. The diversity of the values confirms that each grain is characterized by a different internal structure. Such a diversification can indicate low quality of the grain and poor conditions of cultivation.

Table 2. Results of correlation analysis between the volume of grain and its strength properties.

\begin{tabular}{ccccccccc}
\hline & & $\boldsymbol{F}_{\min }{ }^{\mathbf{1}}$ & $\boldsymbol{F}_{\max }{ }^{2}$ & $\boldsymbol{C}_{\boldsymbol{k}}{ }^{\mathbf{3}}$ & $\boldsymbol{\sigma}_{\min }{ }^{\mathbf{4}}$ & $\boldsymbol{\sigma}_{\max }{ }^{\mathbf{5}}$ & $\boldsymbol{W}_{\boldsymbol{F m i n}}{ }^{\mathbf{6}}$ & $\mathbf{W}_{\text {Fmax }}{ }^{\mathbf{7}}$ \\
\hline \multirow{3}{*}{$V_{\rho}$} & rhoSpearman coefficient & 0.172 & 0.176 & 0.242 & -0.018 & -0.052 & 0.071 & -0.057 \\
& Significance & 0.088 & 0.08 & 0.015 & 0.859 & 0.604 & 0.482 & 0.573 \\
& Number of samples $n$ & 100 & 100 & 100 & 100 & 100 & 100 & 100 \\
\hline \multirow{2}{*}{$V_{\mathrm{s}}$} & rhoSpearman coefficient & 0.220 & 0.062 & 0.005 & -0.280 & -0.104 & 0.185 & -0.138 \\
& Significance & 0.028 & 0.543 & 0.958 & 0.005 & 0.305 & 0.066 & 0.174 \\
& Number of samples $n$ & 100 & 100 & 100 & 100 & 100 & 100 & 100
\end{tabular}

1 Minimal crushing force, ${ }^{2}$ Maximal crushing force, ${ }^{3}$ Minimal compressive stress, ${ }^{4}$ Maximal compressive stress,

${ }^{5}$ Stiffness, ${ }^{6}$ Work for the first rupture, ${ }^{7}$ Rupture work. 
It is noteworthy that the grains were tested for only one orientation of grains in the strength testing machines. It is expected that the longitudinal and transverse orientation of grains would provide different values of destructive compression, forces and strength [28-30].

\section{Conclusions}

The main objectives of the study were achieved through the determination of energy (work) and compressive forces in the test of static compression and analysis of the dependence between the grain size and the grain strength parameters and grinding energy.

Based on the analyzes, it was found that the average grain length of rice was $6.38 \mathrm{~mm}$, the average width was $1.91 \mathrm{~mm}$, the average height was $1.51 \mathrm{~mm}$. The average grain volume determined on the basis of the grain weight and density was equal to $14.82 \mathrm{~mm}^{3}$, while the volume determined on the basis of grain size $18.44 \mathrm{~mm}^{3}$. The correction factor for given volumes $V_{\rho}$ and vs. assumed an average value of 0.82 . The values of the grain dimension distribution can be a determinant in selection of structural features of the materials used, that is, performance parameters of roller mills: diameters of rollers and the size of the inter-roller gap; selection of the screen eye sieve

The average values of strength properties of rice grains were determined, such as $F_{\text {min }}=117.9 \mathrm{~kg} \cdot \mathrm{m} \mathrm{s}^{-2}, F_{\max }=174.99 \mathrm{~kg} \cdot \mathrm{m} \cdot \mathrm{s}^{-2}, \sigma_{\min }=9.80 \mathrm{MPa}, \sigma_{\max }=14.71 \mathrm{MPa}, C_{k}=1150.26 \mathrm{~N} \cdot \mathrm{mm}^{-1}$, $W_{\text {Fmin }}=7.26 \mathrm{~mJ}, W_{\text {Fmax }}=28.03 \mathrm{~mJ}$, which coincided with the results of research carried out by other researchers. The determined ranges of forces, strength and compressive energy (work) are of applicable character and can be used in the design of machines dedicated to process rice. Knowing these values will allow, among others, the estimation of the power of devices, e.g., grinding machines, and roller mills, and in consequence, will minimize energy losses and energy demand for dedicated machines.

The analysis of the Spearman correlation showed that there are no statistically significant relationships between the volume $V_{\rho}$ of the grain and the tested strength properties, so there are no interdependencies between the variables. In the case of the grain size volume vs. a low negative correlation between strength $\sigma_{\min }$ and low positive correlation between the force inducing the first crack (Table 2) were found. Dependence of grinding energy proportionality and the grain mass as well as clear, distinct dependencies between the grain thickness and the value of force and work (low negative correlation between thickness $\operatorname{co} a_{3}$ and stresses $\sigma_{\min }$ and work $W_{F \max }$, low positive correlation between thickness $a_{3}$ and force inducing the first crack $F_{m i n}$ ), that was proven for other biological grainy materials (wheat grains) could not be confirmed either. Based on these results, it was not possible to find significant dependencies between the grain cross-section $A_{0}$ and the values of compressive strength (only low negative correlations were found).

Based on the conducted tests, the crack was found to be different for each grain (Figure 9). The results, including the scatter of dimensions and volume, confirm the high variability and diversity of biological materials within one species. Diversification of the obtained values confirms that each grain is characterized by a different internal structure. Such a differentiation can indicate a poor quality of grain and weak cultivation conditions.

An analysis of the test results of rice grain strength properties provides the basis for determining the impact of biomass properties on the grinding process and, in subsequent stages, for the development of procedures for monitoring the grinding process using energy-environmental grinding efficiency models, the original $\mathrm{CO}_{2}$ emission index for the intelligent monitoring system of usable characteristics of the grinding process.

The results can be used by other researchers to create models of materials (rice grains) for computer simulations of cracking, crushing, mixing using the discrete element method DEM.

Supplementary Materials: The following are available online at http://www.mdpi.com/2071-1050/12/2/552/s1, Table S1: Results of correlation analysis between the size of grain and its strength properties

Author Contributions: Conceptualization, W.K. and J.F.; methodology, W.K. and R.K.; software, W.K. and P.B.-W.; formal analysis, A.M., A.T., and J.F.; investigation, W.K., K.P. and P.B.-W.; resources, W.K.; data curation, A.M., K.P. and R.K.; writing—original draft preparation, W.K., P.B.-W., and A.T; writing—review and editing, W.K., R.K. and 
J.F.; visualization, W.K.; supervision, A.T., J.F., A.M. and K.P.; project administration, W.K.; funding acquisition, W.K. All authors have read and agreed to the published version of the manuscript.

Funding: Scientific work financed by the budget resource for science in 2017-2021, as a research project under the "Diamentowy Grant" program. This research was funded by MINISTRY OF SCIENCE AND HIGHER EDUCATION OF POLAND, grant number DI2016 001646.

Conflicts of Interest: The authors declare no conflict of interest. The funders had no role in the design of the study; in the collection, analyses, or interpretation of data; in the writing of the manuscript, or in the decision to publish the results.

\section{List of Symbols}

$a_{1} \quad$ length of the grain: $\mathrm{mm}$

$a_{2} \quad$ width of the grain, $\mathrm{mm}$

$a_{3} \quad$ height of the grain, $\mathrm{mm}$

$V_{s} \quad$ grain volume calculated based on three dimensions $a_{1}, a_{2}, a_{3}, \mathrm{~mm}^{3}$

$V_{\rho} \quad$ grain volume calculated based on the volumetric mass density, $\mathrm{mm}^{3}$

$\rho \quad$ volumetric mass density, $\mathrm{kg} \cdot \mathrm{m}^{-3}$

$m \quad$ grain weight, $\mathrm{g}$

$k_{v} \quad$ correction coefficient of the grain volume

$R_{c} \quad$ compressive strength, $\mathrm{MPa}$

$F_{c}$ the largest value of the compressive load at which the sample is crushed, $\mathrm{kg} \cdot \mathrm{m} \cdot \mathrm{s}^{-2}$

$A_{0}$ the initial cross-section of the sample, $\mathrm{m}^{2}$

$F \quad$ compressive force, $\mathrm{kg} \mathrm{m} \cdot \mathrm{s}^{-2}$

$\Delta l \quad$ sample shortening corresponding to force $(F), \mathrm{m}$

$l \quad$ the initial length of the sample, $\mathrm{m}$

$A_{0} \quad$ area of the initial sample cross-section, $\mathrm{m}^{2}$

$s \quad$ displacement, $\mathrm{m}$

W work, J

$d W \quad$ elementary work, $\mathrm{J}$

$d s \quad$ elementary displacement, $\mathrm{m}$

$F_{\text {min }} \quad$ minimal crushing force, $\mathrm{kg} \cdot \mathrm{m} \mathrm{s}^{-2}$

$F_{\text {max }} \quad$ maximal crushing force, $\mathrm{kg} \cdot \mathrm{m} \cdot \mathrm{s}^{-2}$

$\sigma_{\text {kmin }}$ minimal compressive stress, $\mathrm{MPa}$

$\sigma_{\text {kmax }}$ maximal compressive stress, $\mathrm{MPa}$

$C_{k} \quad$ stiffness, $\mathrm{N} \cdot \mathrm{mm}^{-1}$

$W_{\text {Fmin }} \quad$ work for the first rupture, $\mathrm{mJ}$

$W_{\text {Fmax }}$ rupture work, $\mathrm{mJ}$

\section{References}

1. Tomporowski, A.; Flizikowski, J.; Kruszelnicka, W. A new concept of roller-plate mills. Przem. Chem. 2017, $96,1750-1755$.

2. Tomporowski, A.; Flizikowski, J.; Wełnowski, J.; Najzarek, Z.; Topoliński, T.; Kruszelnicka, W.; Piasecka, I.; Śmigiel, S. Regeneration of rubber waste using an intelligent grinding system. Przem. Chem. 2018, 97, 1659-1665.

3. Flizikowski, J.B.; Mrozinski, A.; Tomporowski, A. Active monitoring as cognitive control of grinders design. In AIP Conference Proceedings; AIP Publishing: Melville, NY, USA, 2017; Volume 1822, p. 020006.

4. Marczuk, A.; Caban, J.; Savinykh, P.; Turubanov, N.; Zyryanov, D. Maintenance research of a horizontal ribbon mixer. Eksploat. Niezawodn. 2017, 19, 121-125. [CrossRef]

5. Tomporowski, A.; Flizikowski, J. Motion characteristics of a multi-disc grinder of biomass grain. Przem. Chem. 2013, 92, 498-503.

6. Bochat, A.; Zastempowski, M. Kinematics and dynamics of the movement of the selected constructions of the disc cutting assemblies. In Proceedings of the Engineering Mechanics 2017, Brno University of Technology, Faculty of Mechanical Engineering, Institute of Solid Mechanics, Mechatronics and Biomechanics, Brno-Svratka, Czech Republic, 15-18 May 2017; Volume 23, pp. 170-173. 
7. Zastempowski, M.; Bochat, A. Modeling of cutting process by the shear-finger cutting block. Appl. Eng. Agric. 2014, 30, 347-353.

8. Flizikowski, J.; Macko, M. Method of estimation of efficiency of quasi-cutting of recycled opto-telecommunication pipes. Polimery 2001, 46, 53-59. [CrossRef]

9. Kaczmarczyk, J.; Grajcar, A. Numerical simulation and experimental investigation of cold-rolled steel cutting. Materials 2018, 11, 1263. [CrossRef] [PubMed]

10. Kruszelnicka, W.; Shchur, T. Study of rice and maize grains grinding energy. TEKA Comm. Mot. Energetics Agric. 2018, 18, 71-74.

11. Szyszlak-Barglowicz, J.; Zajac, G. Distribution of heavy metals in waste streams during combustion of Sida hermaphrodita (L.) Rusby biomass. Przem. Chem. 2015, 94, 1723-1727.

12. Szyszlak-Bargłowicz, J.; Zając, G.; Słowik, T. Hydrocarbon emissions during biomass combustion. Polish J. Environ. Stud. 2015, 24, 1349-1354. [CrossRef]

13. Kowalczyk-Jusko, A.; Kowalczuk, J.; Szmigielski, M.; Marczuk, A.; Jozwiakowski, K.; Zarajczyk, K.; Maslowski, A.; Slaska-Grzywna, B.; Sagan, A.; Zarajczyk, J. Quality of biomass pellets used as fuel or raw material for syngas production. Przem. Chem. 2015, 94, 1835-1837.

14. Rudnicki, J.; Zadrag, R. Technical state assessment of charge exchange system of self-ignition engine, based on the exhaust gas composition testing. Polish Marit. Res. 2017, 24, 203-212. [CrossRef]

15. Nizamuddin, S.; Qureshi, S.S.; Baloch, H.A.; Siddiqui, M.T.H.; Takkalkar, P.; Mubarak, N.M.; Dumbre, D.K.; Griffin, G.J.; Madapusi, S.; Tanksale, A. Microwave hydrothermal carbonization of rice straw: Optimization of process parameters and upgrading of chemical, fuel, structural and thermal properties. Materials 2019, 12, 403. [CrossRef] [PubMed]

16. Chang, K.-L.; Wang, X.-Q.; Han, Y.-J.; Deng, H.; Liu, J.; Lin, Y.-C. Enhanced enzymatic hydrolysis of rice straw pretreated by oxidants assisted with photocatalysis technology. Materials 2018, 11, 802. [CrossRef] [PubMed]

17. Mannheim, V. Examination of thermic treatment and biogas processes by Lca. Ann. Fac. Eng. Hunedoara Int. J. Eng. 2014, 12, 225-234.

18. Zeng, Y.; Jia, F.; Xiao, Y.; Han, Y.; Meng, X. Discrete element method modelling of impact breakage of ellipsoidal agglomerate. Powder Technol. 2019, 346, 57-69. [CrossRef]

19. Sadeghi, M.; Araghi, H.A.; Hemmat, A. Physico-mechanical properties of rough rice (Oryza sativa L.) Grain as affected by variety and moisture content. Agric. Eng. Int. CIGR J. 2010, 12, 129-136.

20. Cao, W.; Nishiyama, Y.; Koide, S. Physicochemical, mechanical and thermal properties of brown rice grain with various moisture contents. Int. J. Food Sci. Technol. 2004, 39, 899-906. [CrossRef]

21. Chattopadhyay, P.K.; Hamann, D.D.; Hammerle, J.R. Effect of deformation rate and moisture content on rice grain stiffness1. J. Food Process Eng. 1980, 4, 117-121. [CrossRef]

22. Buggenhout, J.; Brijs, K.; Celus, I.; Delcour, J.A. The breakage susceptibility of raw and parboiled rice: A review. J. Food Eng. 2013, 117, 304-315. [CrossRef]

23. Esehaghbeygi, A.; Daeijavad, M.; Afkarisayyah, A.H. Breakage susceptibility of rice grains by impact loading. Appl. Eng. Agric. 2009, 25, 943-946. [CrossRef]

24. Sarker, M.S.H.; Hasan, S.M.K.; Ibrahim, M.N.; Aziz, N.A.; Punan, M.S. Mechanical property and quality aspects of rice dried in industrial dryers. J. Food Sci. Technol. 2017, 54, 4129-4134. [CrossRef] [PubMed]

25. Talab, K.T.; Ibrahim, M.N.; Spotar, S.; Talib, R.A.; Muhammad, K. Glass transition temperature, mechanical properties of rice and their relationships with milling quality. Int. J. Food Eng. 2012, 8.

26. Nasirahmadi, A.; Abbaspour-Fard, M.H.; Emadi, B.; Khazaei, N.B. Modelling and analysis of compressive strength properties of parboiled paddy and milled rice. Int. Agrophysics 2014, 28, 73-83. [CrossRef]

27. Bonazzi, C.; Courtois, F. Impact of drying on the mechanical properties and crack formation in rice. In Modern Drying Technology; John Wiley \& Sons, Ltd.: Hoboken, NJ, USA, 2011; pp. 21-49. ISBN 978-3-527-63166-7.

28. Li, Y.-N.; Li, K.; Ding, W.-M.; Chen, K.-J.; Ding, Q. Correlation between head rice yield and specific mechanical property differences between dorsal side and ventral side of rice kernels. J. Food Eng. 2014, 123, 60-66. [CrossRef]

29. Shu, Y.-J.; Liou, N.-S.; Moonpa, N.; Topaiboul, S. Investigating damage properties of rice grain under compression load. In Proceedings of the International Conference on Experimental Mechanics 2013 and Twelfth Asian Conference on Experimental Mechanics, Bangkok, Thailand, 25-27 November 2013; International Society for Optics and Photonics: Bangkok, Thailand, 2014; Volume 9234, p. 923402. 
30. Zareiforoush, H.; Komarizadeh, M.H.; Alizadeh, M.R.; Tavakoli, H.; Masoumi, M. Effects of moisture content, loading rate, and grain orientation on fracture resistance of paddy (Oryza sativa L.) grain. Int. J. Food Prop. 2012, 15, 89-98. [CrossRef]

31. Zareiforoush, H.; Komarizadeh, M.H.; Alizadeh, M.R. Mechanical properties of paddy grains under quasi-static compressive loading. N. Y. Sci. J. 2010, 3, 40-46.

32. Pandiselvam, R.; Thirupathi, V.; Mohan, S. Engineering properties of rice. Agric. Eng. 2015, XL, 69-78.

33. Ligaj, B.; Szala, G. Obliczanie zapotrzebowania energii w procesach rozdrabniania materiałów ziarnistych na przykładzie ziaren zbóż. Acta Mech. Autom. 2009, 3, 97-99.

34. Tumuluru, J.S.; Tabil, L.G.; Song, Y.; Iroba, K.L.; Meda, V. Grinding energy and physical properties of chopped and hammer-milled barley, wheat, oat, and canola straws. Biomass Bioenergy 2014, 60, 58-67. [CrossRef]

35. Wiercioch, M.; Niemiec, A.; Roma, L. The impact of wheat seeds size on energy consumption of their grinding process. Inzyneria Rol. 2008, 103, 367-372.

36. Warechowska, M. Some physical properties of cereal grain and energy consumption of grinding. Agric. Eng. 2014, 1, 239-249.

37. Dziki, D.; Laskowski, J. Influence of wheat kernel geometrical properties on the mechanical properties and grinding ability. Acta Agrophysica 2003, 2, 735-742.

38. Warechowska, M.; Warechowski, J.; Skibniewska, K.A.; Siemianowska, E.; Tyburski, J.; Aljewicz, M.A. Environmental factors influence milling and physical properties and flour size distribution of organic spelt wheat. Tech. Sci. 2016, 19, 387-399.

39. Dziki, D. Ocena energochłonności rozdrabniania ziarna pszenicy poddanego uprzednio zgniataniu. Inzyneria Rol. 2007, 11, 51-58.

40. Dziki, D.; Cacak-Pietrzak, G.; Miś, A.; Jończyk, K.; Gawlik-Dziki, U. Influence of wheat kernel physical properties on the pulverizing process. J. Food Sci. Technol. 2014, 51, 2648-2655. [CrossRef] [PubMed]

41. Greffeuille, V.; Mabille, F.; Rousset, M.; Oury, F.-X.; Abecassis, J.; Lullien-Pellerin, V. Mechanical properties of outer layers from near-isogenic lines of common wheat differing in hardness. J. Cereal Sci. 2007, 45, 227-235. [CrossRef]

42. Greffeuille, V.; Abecassis, J.; Barouh, N.; Villeneuve, P.; Mabille, F.; Bar L’Helgouac'h, C.; Lullien-Pellerin, V. Analysis of the milling reduction of bread wheat farina: Physical and biochemical characterisation. J. Cereal Sci. 2007, 45, 97-105. [CrossRef]

43. Yenge, G.B.; Kad, V.P.; Nalawade, S.M. Physical properties of maize (Zea mays L.) grain. J. Krishi Vigyan 2018, 7, 125-128. [CrossRef]

44. Korczewski, Z.; Rudnicki, J. An energy approach to the fatigue life of ship propulsion systems marine 2015. In Proceedings of the VI International Conference on Computational Methods in Marine Engineering-The Conference Proceedings, Rome, Italy, 14-17 July 2015; Salvatore, F., Broglia, R., Muscari, R., Eds.; International Center Numerical Methods Engineering: Barcelona, Spain, 2015; pp. 490-501, ISBN 978-84-943928-6-3.

45. Lu, R.; Siebenmorgen, T.J. Correlation of head rice yield to selected physical and mechanical properties of rice kernels. Trans. ASAE 1995, 38, 889-894. [CrossRef]

(C) 2020 by the authors. Licensee MDPI, Basel, Switzerland. This article is an open access article distributed under the terms and conditions of the Creative Commons Attribution (CC BY) license (http://creativecommons.org/licenses/by/4.0/). 